\title{
Research on Stator Core with Crushed pieces of Nanocrystalline Soft Magnetic Alloy
}

\author{
Tuyoshi Nonaka*a) Member, Shogo Makino* Member \\ (Manuscript received Jan. 00, 20XX, revised May 00, 20XX)
}

\begin{abstract}
NANOMET is one of the several nanocrystalline soft magnetic alloys ${ }^{(1)}$. The authors already reported about the prototype motor with NANOMET stator cores ${ }^{(2)}$. In this paper, the authors reported that NANOMET core motor has low iron loss characteristics which cannot be achieved with $35 \mathrm{~A} 360$ core motor, while maintaining the torque density comparable to that of $35 \mathrm{~A} 360$ core motor. In order to reduce the mass production cost of the currently expensive NANOMET stator cores and promote its practical application, we have devised molding of crushed NANOMET into a stator core. This paper describes about crushed NANOMET toroidal core, and presents the evaluation results of the iron loss characteristics.
\end{abstract}

Keywords : NANOMET, Nanocrystalline soft magnetic alloy, Crushed pieces, Low iron loss

\section{Background and issue}

Making existing motors more compact, more powerful and more efficient is an eternal challenge (3), (4). Permanent magnet synchronous motors are at the forefront of overcoming these challenges. In order to further reduce the size and increase the output of permanent magnet synchronous motors, it is effective to increase the magnetic loading or electric loading, and to further enhance the mechanical strength of the motor for high-speed rotation, especially strengthening the centrifugal resistance of the rotor. The authors have already proposed "flux concentration IPM motor" (5) that increases the gap flux density by about 1.5 times as a method of increasing magnetic loading. As a method of increasing electrical loading, we proposed "press-formed coil" (6) with a coil space factor of $90 \%$ or more. For strengthening the rotor's centrifugal resistance, "high-strength steel plate rotor core" (7), which uses a high-strength steel plate with a yield point more than three times that of conventional electromagnetic steel plates, was proposed. A maximum peripheral speed of $190 \mathrm{~m} / \mathrm{s}$ was achieved with an IPM rotor. An example of a motor that combines these technologies is the prototype motor (mass $14 \mathrm{~kg}$ ) shown in Fig.1. It generates $29 \mathrm{~kW}$ at a base rotational speed of $3000 \mathrm{~min}^{-1}$, but with a imagined motor as shown in Fig.2, the stack thickness $46 \mathrm{~mm}$ is tripled and the base rotational speed is increased to 20000 $\mathrm{min}^{-1}$. Based on simple calculation, this motor will generate an output of $580 \mathrm{~kW}$ (mass $29 \mathrm{~kg}$ ). Recently, there is a demand for the development of aircraft motors, and the target power density at maximum output is said to be $10 \mathrm{~kW} / \mathrm{kg}{ }^{(8)}$, but that target can be achieved based on the calculation shown above.

While achieving maximum output, it is important to reduce loss in order to achieve rated output. In particular, the iron loss

This paper is based on Reference (13), which published in the International Conference ICEMS (2020) (C2020 IEEJ.

a) Correspondence to: Tuyoshi Nonaka. E-mail:

Tuyoshi.Nonaka@yaskawa.co.jp

* YASKAWA ELECTRIC CORPORATION.

12-1 Ohtemachi, Kokurakita-ku, Kitakyushu 803-8530, Japan

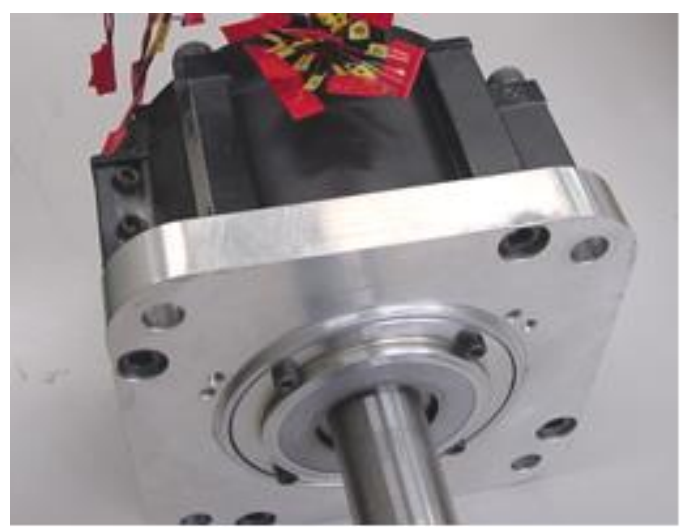

Fig. 1. Prototype motor.

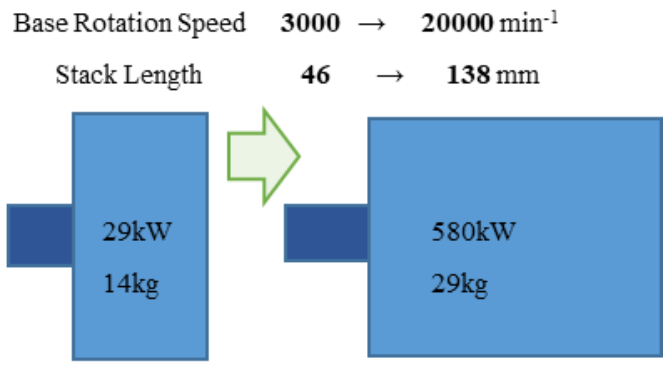

Fig. 2. Imagined motor.

generated in the stator core increases as the magnetic flux density and rotational speed increase. The application of nanocrystalline soft magnetic alloys is promising as a countermeasure. A Prototype motor shown in Fig.1 was manufactured by applying NANOMET sheets to the stator core after being optimally heattreated by the manufacturer. We concluded that the stator core iron loss was reduced to less than half that of the conventional electromagnetic steel sheet $35 \mathrm{~A} 360^{(2)}$.

With the above technological development, it is technically 
possible to make existing motors more compact, more powerful and more efficient, but there remains a major problem that the manufacturing cost of NANOMET stator core will be extremely expensive. Since NANOMET sheets used in Ref. (2) are as thin as $0.025 \mathrm{~mm}$, it takes a lot of effort to stack it to the specified thickness and process it into the design shape. In addition, NANOMET sheets are expected to be several times more expensive than the conventional electrical steel sheet due to the cost required for the process leading to nanocrystallization, ensuring uniform thickness and surface roughness.

In order to solve the problem, the authors devised to mold the crushed NANOMET into a stator core shape. As a first trial, NANOMET sheets are crushed and the crushed pieces were used to form a toroidal core. Efforts were made to improve the space factor, and its characteristics were compared and evaluated with other materials. The results and the findings obtained are reported.

\section{Consideration of Crushed Pieces}

NANOMET is a Fe-Si-B-P-Cu-based nanocrystalline soft magnetic alloys that has a high saturation magnetic flux density of over $1.8 \mathrm{~T}$, a low coercive force of $10 \mathrm{~A} / \mathrm{m}$ or less, and a low iron loss value of approximately $0.4 \mathrm{~W} / \mathrm{kg}\left(\mathrm{W}_{17 / 50}\right)$, it is expected to be applied to electric machinery and apparatus such as motors ${ }^{(1)}$. Compared with $35 \mathrm{~A} 360$, which is one of the conventional electromagnetic steel sheets, NANOMET has low iron loss due to its low coercive force and thin sheet ${ }^{(2)}$, and since the saturation magnetic flux density is equivalent to $35 \mathrm{~A} 360$, it is expected to achieve the same high torque density as the conventional one. In order to solve the problem of the high cost of NANOMET stator core, we considered specific measures to mold the crushed pieces of NANOMET into a stator core shape.

2.1 Consideration of sheet manufacturing process NANOMET is made into a thin sheet by the rapid solidification method from molten alloy, and then heat-treated to obtain low iron loss characteristics ${ }^{(9)}$. According to the Ref. (9), the stator core is manufactured through the steps of (A) production of a quenched sheet, (B) processing into a stator core shape, (C) crystallization heat treatment, and (D) lamination. In order to process (B), it is necessary to move from the sheet production line of (A), and crystallization heat treatment requires a rapid temperature change, so the processed stator core is heat-treated without lamination ${ }^{(9)}$. Careful handling is required to stack the individual sheets that have become brittle by the crystallization heat treatment.

When molding the crushed pieces of NANOMET into the shape of a stator core, not only steps (B) and (D) are omitted, but also steps (A) and (C) can be performed continuously, so it is thought that the manufacturing cost of NANOMET stator core will be improved. Furthermore, if it is to be a crushed piece, it is not necessary to arrange it to a specified width and the sheets need not be continuous. The material of the crushed pieces does not have to be a thin sheet, and it is sufficient if it is in the form of a plate, and it can be filled into a bucket to be a product. It is expected that such materials can be purchased at a low unit price by weight.

2.2 Consideration about thickness Iron loss is classified into hysteresis loss and eddy current loss and is shown by the following equation ${ }^{(10)}$.

$$
w_{f}=B^{2}\left\{\sigma_{h}\left(\frac{f}{100}\right)+\sigma_{e} d^{2}\left(\frac{f}{100}\right)^{2}\right\}
$$

where $w_{f}$ is iron loss per $1 \mathrm{~kg}$. $f$ is frequency. $\sigma_{h}$ is hysteresis coefficient. $\sigma_{e}$ is eddy current coefficient. $B$ is magnetic flux density. $\quad d$ is steel plate thickness.

When verifying the iron loss generated in the motor with the measured values, if equation (1) is expressed by the torque $T_{f}$ generated by the iron loss, the hysteresis loss and eddy current loss can be easily analyzed. Substituting Eq. (2), (3), and (4) into Eq. (1) gives Eq. (5). The previous term shows the torque due to hysteresis loss, and the latter term shows the torque due to eddy current loss. The former has a constant value with respect to the rotational speed of the motor, and the latter has a value proportional to the rotational speed.

$$
w_{f}=\frac{W_{f}}{M}
$$

where $W_{f}$ is iron loss. $\quad M$ is mass of stator core.

$$
W_{f}=T_{f} N \frac{2 \pi}{60}
$$

where $T_{f}$ is torque generated by the iron loss. $\quad N$ is rotational speed per minute.

$$
f=N \frac{p}{60}
$$

where $p$ is pair of poles number.

$$
T_{f}=\frac{M B^{2}}{2 \pi}\left\{\frac{p}{100} \sigma_{h}+\frac{N}{60}\left(\frac{p}{100}\right)^{2} d^{2} \sigma_{e}\right\}
$$

By substituting the values shown in Table 1, which are the design specifications of the prototype motor with conventional steel sheet shown in Fig.1, into Equation (5), Equation (6) is obtained, and $\sigma_{h}$ and $\sigma_{e}$ shown in Table 2 are obtained.

$$
T_{f}=0.0627 \sigma_{h}+0.0096 \sigma_{e}
$$

Applying the high-strength steel plate rotor core ${ }^{(7)}$ to increase the base rotational speed of the prototype motor to $20000 \mathrm{~min}^{-1}$, and studying the motors with the values shown in Table 2, equation (7) represents the torque generated by the iron loss with $d$ as a variable. The previous term is the torque generated by the hysteresis loss, and the next term is the torque generated by the eddy current loss.

Table 1. Specification of Prototype motor.

\begin{tabular}{|c|c|}
\hline Torque due to iron loss $: T_{f}$ & $0.6 \mathrm{~N} \cdot \mathrm{m}$ \\
\hline Mass of stator core $: M$ & $3.077 \mathrm{~kg}$ \\
\hline Flux density $: B$ & $1.6 \mathrm{~T}$ \\
\hline Number of pole pairs $: p$ & 5 \\
\hline Steel sheet thickness $: d$ & $0.35 \mathrm{~mm}$ \\
\hline Base rotational speed $: N$ & $3000 \mathrm{~min}^{-1}$ \\
\hline
\end{tabular}

Table 2. Set Value for Iron Loss Calculation.

\begin{tabular}{|c|c|}
\hline Hysteresis coefficient $: \sigma_{h}$ & 4.80 \\
\hline Eddy current coefficient $: \sigma_{e}$ & 31.4 \\
\hline Base rotational speed $: N$ & $20000 \mathrm{~min}^{-1}$ \\
\hline Rated torque $: T_{r}$ & $37 \mathrm{~N} \cdot \mathrm{m}$ \\
\hline
\end{tabular}




$$
T_{f}=0.301+2.46 d^{2}
$$

From equation (7), Fig. 3 shows the rated torque ratio generated by the hysteresis loss and the eddy current loss for the thickness of steel sheet. If the torque generated by eddy current loss is designed to be within $1 \%$ of the rated torque, it can be seen that the thickness should be $0.1 \mathrm{~mm}$ or less.

Considering the appropriate thickness of the plate-like NANOMET used for the crushed pieces, it should be smaller to reduce eddy current loss and larger to improve the space factor. The thickness of NANOMET sheet is about $0.025 \mathrm{~mm}$, and it seems appropriate to increase it to about 40 to $80 \mu \mathrm{m}$ in order to improve the space factor. Unlike conventional NANOMET sheet used for lamination, NANOMET for crushed pieces that need only irregularly shaped discontinuous sheet will be mass-produced cheaply for thicker materials by using the double roll method shown in Fig.4(a) and (b), for example.

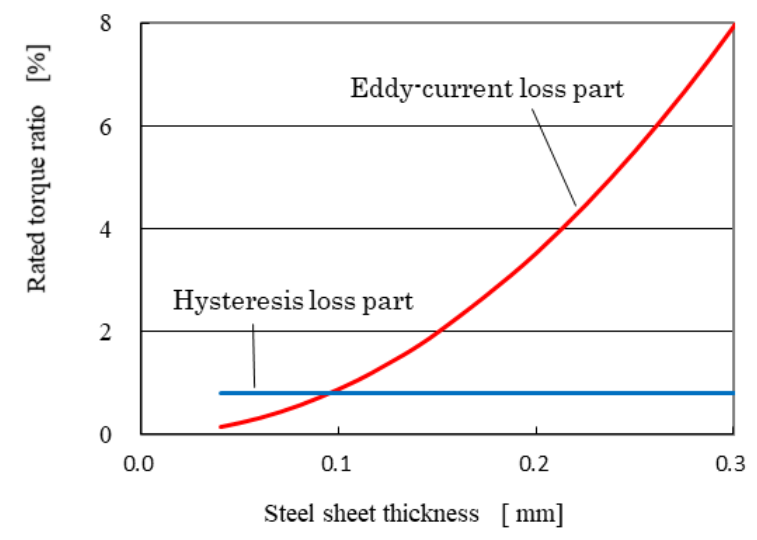

Fig. 3. Torque ratio to steel sheet thickness.

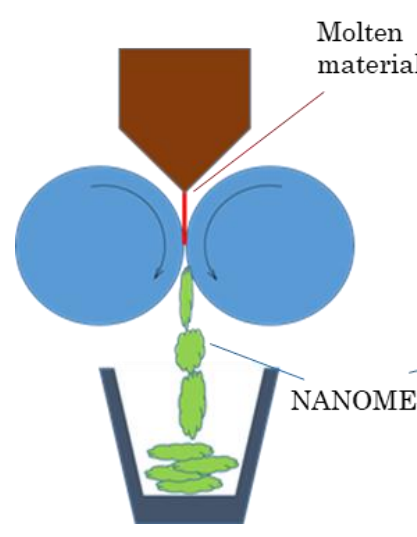

(a)

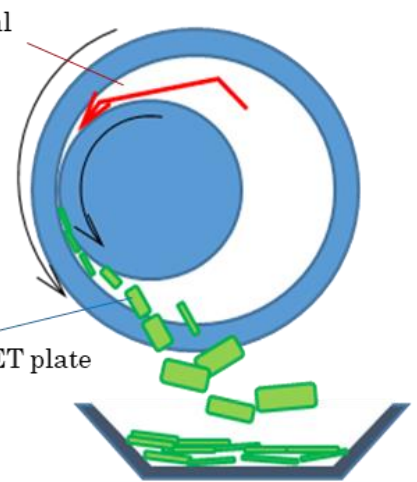

(b)
Fig. 4. Examples of rapid cooling manufacturing method.

\section{Trial Manufacture of NANOMET Crushed Pieces Toroidal Core and Problems}

3.1 Manufacture and space factor improvement In order to evaluate the feasibility of crushed NANOMET stator core, the first attempt was to crush the NANOMET sheet and form it into a toroidal core. Based on the history ${ }^{(11)}$, a toroidal core was prototyped with an outer diameter of $30 \mathrm{~mm}$ and an inner diameter of $20 \mathrm{~mm}$.

Fig. 5 is an overview of the molding process. Fill the mold with crushed pieces of NANOMET (a) and tighten with $8 \mathrm{M} 12$ bolts to compress (b). Dial gauge is used to observe the amount of height deformation of the crushed pieces with respect to the applied pressure. Since the adhesive is added before the pressurization, the excess adhesive is discharged according to the pressurization. The toroidal core is formed by heating to the curing temperature of the adhesive under pressure. Fig. 6 is an overview of crushed pieces of NANOMET used. Initially, NANOMET sheets was purchased from Tokin Co., Ltd. There was a similar trial using the crushed pieces of NANOMET for the 2019 NEDO open call theme (11). The crushed pieces of NANOMET, which are raw materials for iron core materials used in motors and transformers, have been developed there. Therefore, we obtained one from Tohoku Magnet Institute Co., Ltd. (TMI).

Fig.7 shows crushed NANOMET toroidal core manufactured.

If the space factor is defined as the percentage of the material having a specific gravity of 7.8, the initial crushed NANOMET toroidal core was as small as about $70 \%$. The space factor was improved by demagnetizing the delicate magnetism of crushed pieces and instruments.

Fig. 8 is a cross-sectional photograph of crushed NANOMET toroidal core. It was manufactured in the same way as the tightened at $120 \mathrm{~N} \cdot \mathrm{m}$ shown in Table 3 described later, but it is not the same. Except near the inner and outer diameters, most of pieces are perpendicular to the stacking direction. In the process of space factor improvement, it was found that the adhesive impregnated in the crushed pieces was not discharged enough to increase the pressure and the space factor was not improved. Impregnation with an adhesive is essential for forming a toroidal core.

As a result of trial and error, the adhesive was impregnated only in the part near the surface of the toroidal core. The black part inside the cross section of the Fig. 8 is the part without adhesive. With the above improvements, the space factor has been increased to $77 \%$ with the original NANOMET. $75 \%$ is the maximum for TMI's NANOMET. The difference between the two seems to be the brittleness and hardness of the crushed pieces, but no conclusion has been reached.

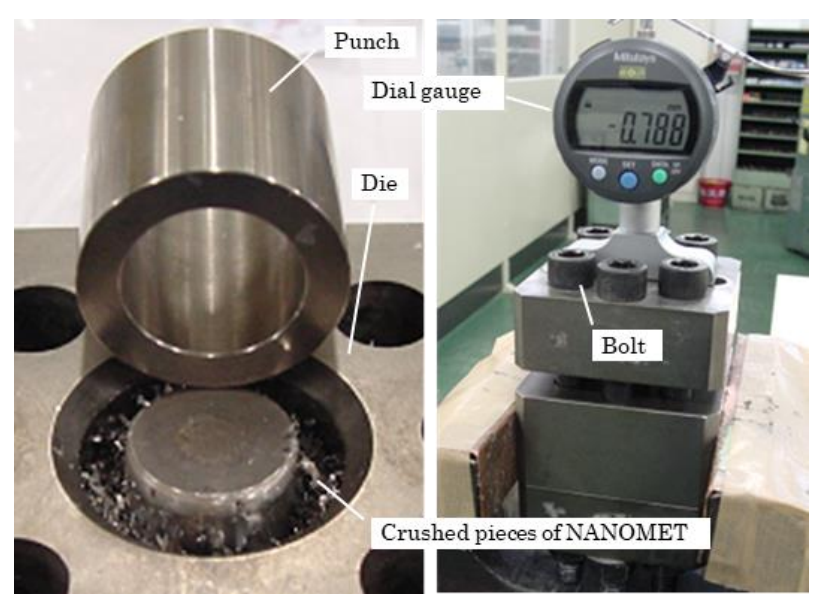

(a)

(b)

Fig. 5. Overview of pressure molding. 


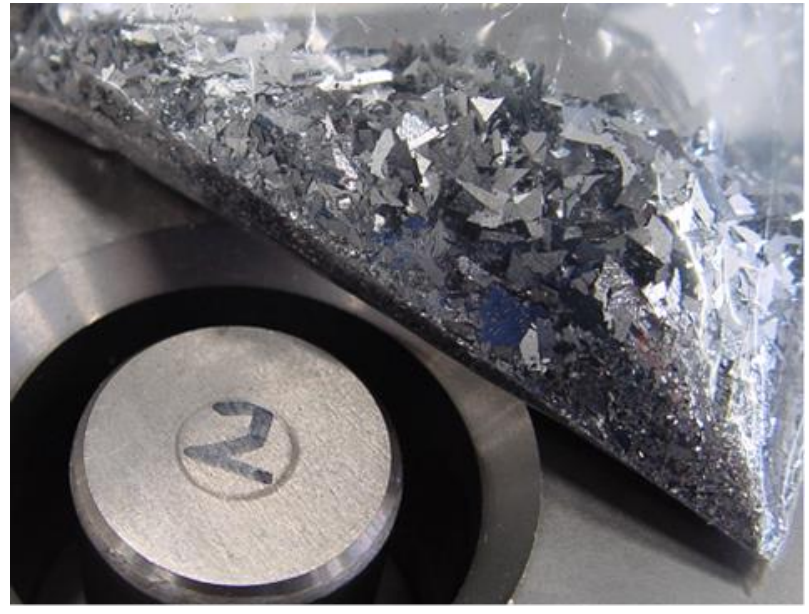

Fig. 6. Crushed pieces of NANOMET.

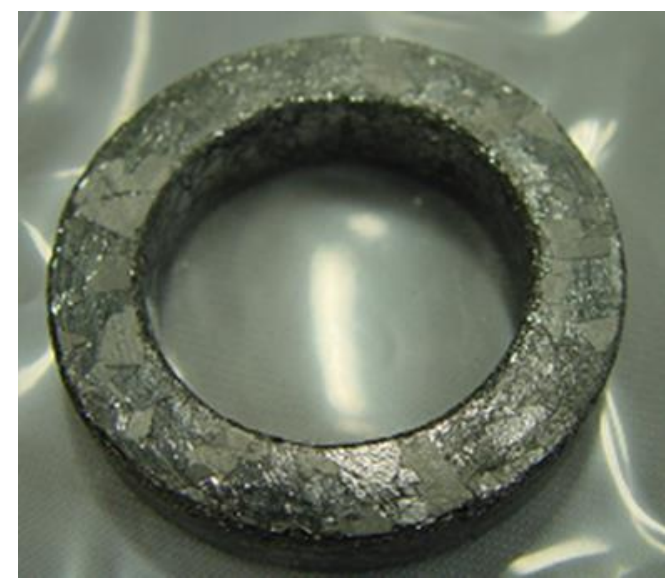

Fig. 7. Crushed NANOMET toroidal core.



Fig.8. Cross-sectional photograph of crushed NANOMET toroidal core.

3.2 Magnetic characteristics of toroidal cores Table 3 shows the specifications of the toroidal core manufactured for magnetic property measurement. Four crushed NANOMET toroidal cores were manufactured by changing the bolt tightening torque in order to clarify the B-H characteristic problem described later. It is calculated that a pressure of about $1000 \mathrm{MPa}$ will be generated when tightened at $120 \mathrm{~N} \cdot \mathrm{m}$. We manufactured a stack of NANOMET sheets purchased separately from TMI (Laminated
Table 3. Spec. of Toroidal Cores.

\begin{tabular}{|c|c|c|c|c|c|c|}
\hline Type & $\begin{array}{c}\text { Tightening } \\
\text { torque } \\
{[\mathrm{N} \cdot \mathrm{m}]}\end{array}$ & $\begin{array}{c}\text { Mass } \\
{[\mathrm{g}]}\end{array}$ & $\begin{array}{c}\text { Hight } \\
{[\mathrm{mm}]}\end{array}$ & $\begin{array}{c}\text { Cross- } \\
\text { sectional } \\
\text { area }\left[\mathrm{mm}^{2}\right]\end{array}$ & $\begin{array}{c}\text { Density } \\
{\left[\mathrm{g} / \mathrm{cm}^{3}\right]}\end{array}$ & $\begin{array}{c}\text { Space factor } \\
{[\%]}\end{array}$ \\
\hline $\begin{array}{c}\text { Crushed } \\
\text { NANOMET }\end{array}$ & 120 & 14.93 & 6.35 & 32.39 & 5.85 & 75.0 \\
\hline $\begin{array}{c}\text { Crushed } \\
\text { NANOMET }\end{array}$ & 80 & 14.85 & 6.80 & 34.51 & 5.46 & 70.0 \\
\hline $\begin{array}{c}\text { Crushed } \\
\text { NANOMET }\end{array}$ & 40 & 15.00 & 7.50 & 38.06 & 5.00 & 64.1 \\
\hline $\begin{array}{c}\text { Crushed } \\
\text { NANOMET }\end{array}$ & 10 & 14.55 & 9.30 & 46.50 & 3.98 & 51.1 \\
\hline $\begin{array}{c}\text { Laminated } \\
\text { NANOMET }\end{array}$ & 120 & 14.82 & 5.34 & 26.62 & 7.11 & 91.1 \\
\hline 10$\lrcorner$ NEX900 & - & 14.74 & 5.28 & 26.45 & 7.10 & 91.1 \\
\hline 35H360 & - & 14.70 & 4.93 & 25.02 & 7.50 & 96.2 \\
\hline
\end{tabular}

NANOMET), as conventional electromagnetic steel sheet, 10JNEX900 made by JFE Steel Co., Ltd. and 35H360 made by Nippon Steel Co., Ltd., for the same weight and compared. The space factor of crushed NANOMET toroidal core is smaller than that of the three laminated toroidal cores. Comparing the four crushed NANOMET toroidal cores, the space factor increased from $51.1 \%$ to $75 \%$ as the tightening torque increased.

Fig.9 shows B-H characteristics comparison of toroidal cores. Laminated NANOMET toroidal core is very easy to magnetize, and shows a magnetization characteristic exceeding 10JNEX900 or $35 \mathrm{H} 360 \mathrm{in}$ most of the measurement range. On the other hand, the low magnetic properties of crushed NANOMET toroidal cores using same NANOMET are remarkable.

To investigate the cause, we compared the B-H characteristics of four crushed NANOMET toroidal cores manufactured with different tightening torque. Fig.10 shows B-H characteristics comparison of that. It can be seen that the curve changes linearly as tightening torque increases, and the magnetic permeability also decreases. The decrease in the magnetic permeability is thought to be due to the following reasons. As the crushed pieces are crushed by the pressure, and gap ratio of the magnetic path increases as the pieces becomes finer, the high permeability property of NANOMET sheet is impaired. Fig.11 shows the difference in coercive force by changing the scale of Fig.10. It can be seen that the coercive force increases as the tightening torque increases. It appears that crushed NANOMET toroidal cores has a coercive force more than double compared to that of laminated toroidal cores, even with a small tightening torque. We find that it is difficult to produce crushed NANOMET stator core for motors with low iron loss simply by increasing the space factor by applying pressure. For example, if the size and shape of crushed pieces are squares with a certain thickness and they can be spread without a gap to form a laminated structure, a core with a high space factor can be manufactured. But we think that using this method will increase the cost because it will not be NANOMET for crushed pieces that need only irregularly shaped discontinuous sheet. That is a major problem for the future.

Fig.12 shows the iron loss characteristics of various toroidal cores at $1.6 \mathrm{kHz} . \quad 1.6 \mathrm{kHz}$ is the fundamental frequency that drives the motor explained in Fig. 1 at the rotational speed of $19200 \mathrm{~min}^{-1}$. Iron loss is a particular problem at high-speed driving, and the comparison result shows the iron loss of crushed NANOMET 


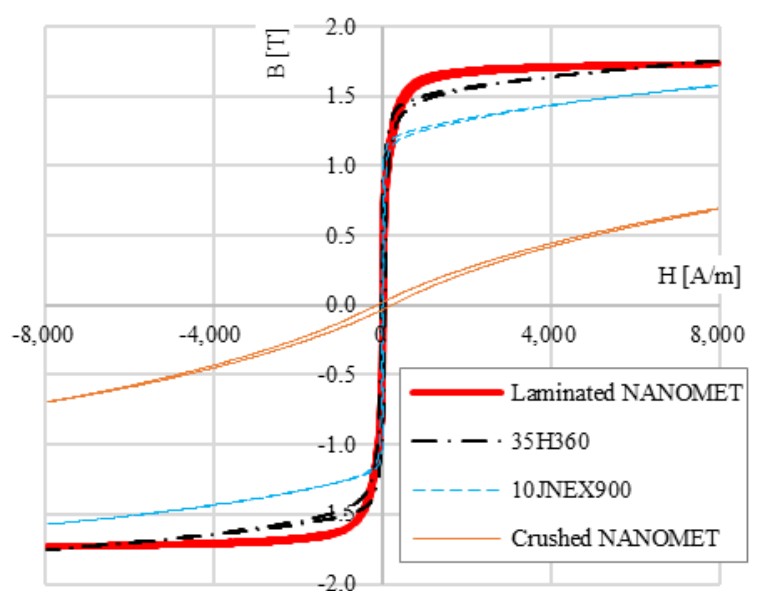

Fig. 9. B-H characteristics comparison of toroidal cores.

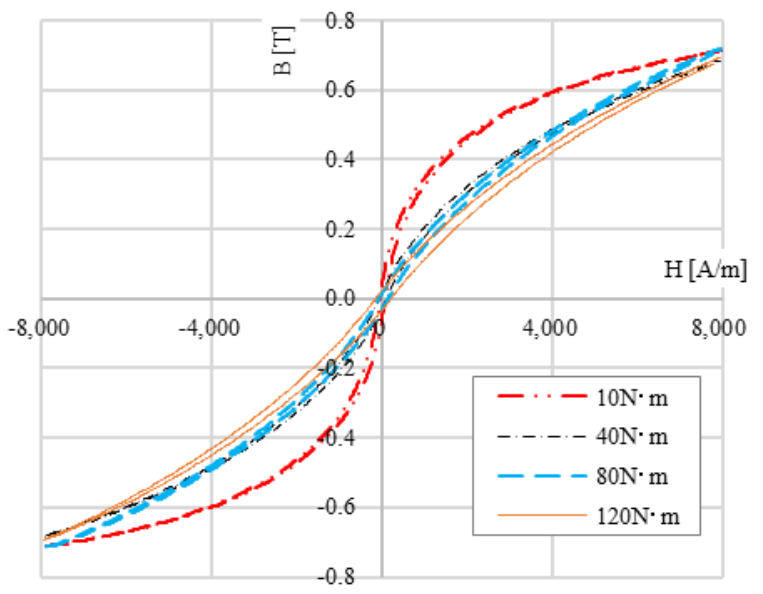

Fig. 10. B-H characteristics comparison.



Fig. 11. The difference in coercive force.

toroidal core is smaller than that of $35 \mathrm{H} 360$. An increase in loss for the laminated NANOMET can also be seen. In addition, the iron loss of the laminated NANOMET, which should have low iron loss, was larger than that of 10JNEX900. Fig.13 shows the iron loss characteristics of various toroidal cores at $0.5 \mathrm{~T}$. In this comparison, the iron loss of crushed NANOMET toroidal core is smaller than $35 \mathrm{H} 360$ at high frequencies, but is large at low frequencies. In this comparison, too, the iron loss of the laminated NANOMET, which should have a low iron loss, was larger than that

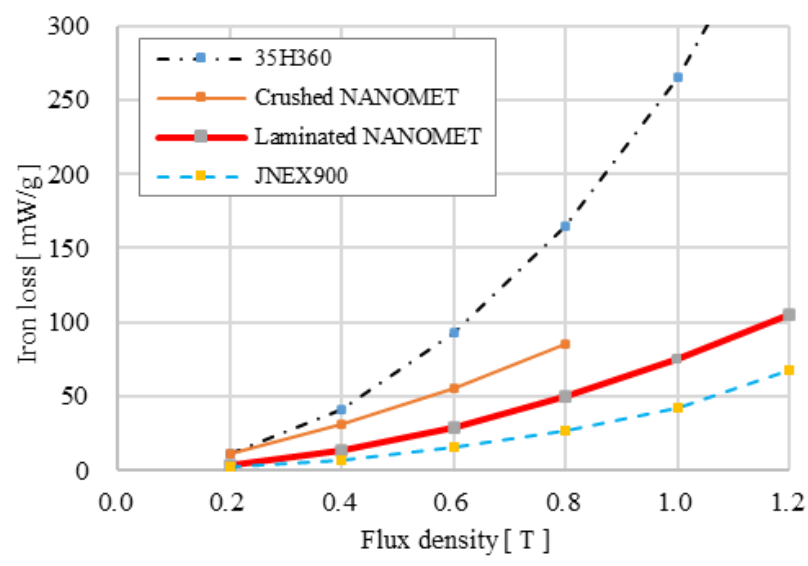

Fig. 12. Iron loss characteristics at $1.6 \mathrm{kHz}$.

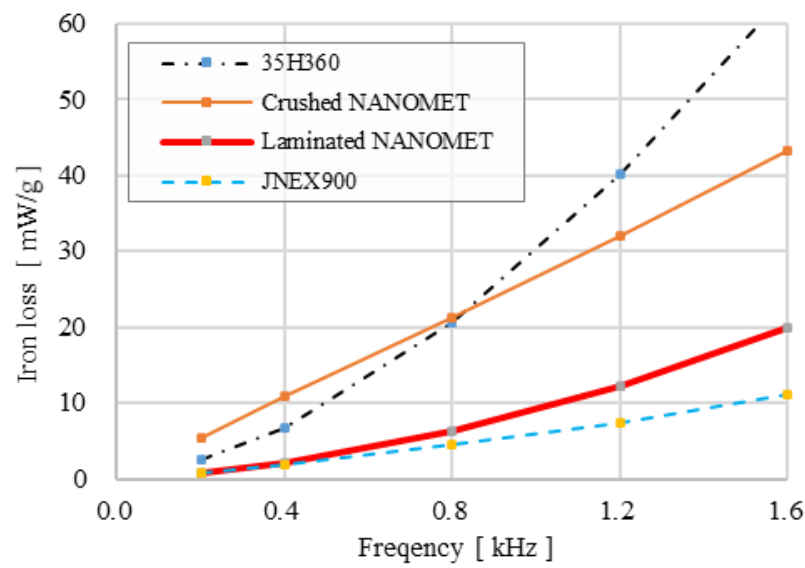

Fig. 13. Iron loss characteristics at $0.5 \mathrm{~T}$.

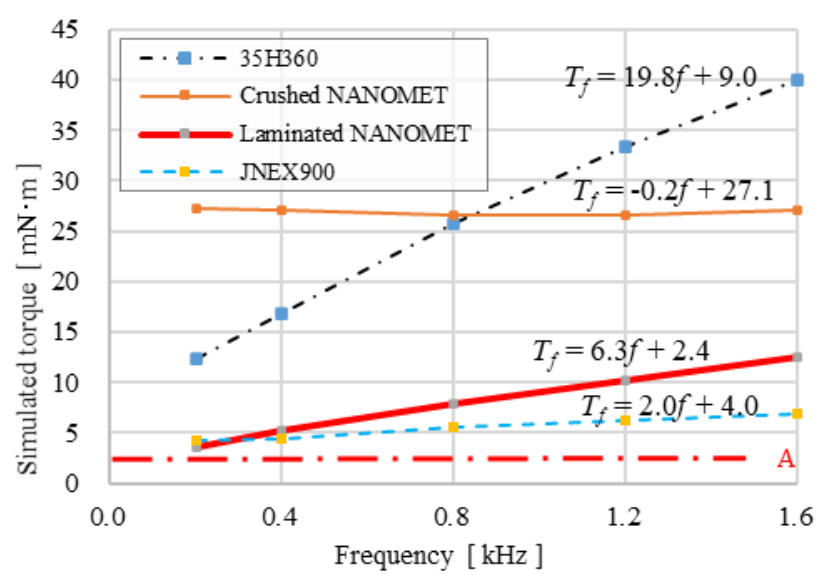

Fig. 14. Simulated torque characteristics at 0.5T.

of 10JNEX900.

It is effective to separate the iron loss into hysteresis loss and eddy current loss as to why this result was obtained. If the value obtained by dividing the iron loss by the frequency is simulated torque, Fig.14 shows a comparison of simulated torque. Formula $T_{f}(f)$ approximated by a first-order line is attached to each characteristic. Each characteristic is theoretically approximated by a first-order line, and the simulated torque at a frequency of $0 \mathrm{~Hz}$ shows the value due to hysteresis loss, and the slope of the firstorder line shows the value due to eddy current loss. As for the 
characteristics of crushed NANOMET, the hysteresis loss is about 3 times larger than that of $35 \mathrm{H} 360$, and it can be seen that there is almost no eddy current loss. The increase in hysteresis loss can be understood because the coercive force shown in Fig.11 is large. The fact that there is almost no eddy current loss is convincing from the consideration results in Fig.3 because the thickness of NANOMET piece is about $0.025 \mathrm{~mm}$. Also, looking at the characteristics of laminated NANOMET, it can be seen that the hysteresis loss is about $3 / 5$ that of $10 \mathrm{JNEX} 900$ and the eddy current loss is more than double. Considering the sheet thickness, the increase in eddy current loss is abnormal. The crushed NANOMET toroidal core was manufactured by molding, while the other three were manufactured by wire cutting from blocks laminated and bonded. Aside from $10 \mathrm{JNEX} 900$ and $35 \mathrm{H} 360$, it is suspected that there will be a leak between the sheets due to wire cutting in laminated NANOMET. Considering that the original eddy current loss of crushed NANOMET is as small as crushed NANOMET, it is conceivable that the characteristics will be like line A.

\section{Conclusions.}

In order to reduce the mass production cost of currently expensive NANOMET stator cores and promote its practical application, we have devised molding of crushed NANOMET into a stator core. Crushed NANOMET toroidal core was molded, and $\mathrm{B}-\mathrm{H}$ characteristics and iron loss characteristics were evaluated.

When the space factor increases by applying pressure, the magnetic permeability rather decreases. Problems such as increasing the gap ratio of the magnetic path and increasing coercive force due to crushing and pulverization during pressure molding remained.

\section{Acknowledgements}

NANOMET is a trademark of Tokin Co., Ltd. and Tohoku Magnet Institute Co., Ltd. This paper is based on results obtained from a project subsidized by the New Energy and Industrial Technology Development Organization (NEDO) ${ }^{(12)}$.

\section{References}

(1) A. Makino, "The Latest Research and Development Trends of Super-Low Core-Loss and High Fe-Content Nanocrystalline Soft Magnetic Alloy "NANOMET"," Materia Japan, Vol.55 No.3, pp.89-96, 2016. (in Japanese)

(2) T. Nonaka, S. Zeze, S. Makino, and M. Ohto, "Research of the Motor with Nanocrystalline Soft Magnetic Alloy Stator Cores,” IEEJ Trans. IA, Vol.139, No.10, pp.873-879, 2019. (in Japanese)

(3) Yuji Enomoto, Kenta Deguchi, Takao Imagawa, "Development of an Ultimate-high-efficiency Motor utilizing High-Bs Nanocrystalline Alloy," IEEJ J. Industry Applications, Vol.9, No.1, pp.102-108, 2020.

(4) Atsuo Kawamura, Satoshi Nakazaki, Shogo Ito, Sakahisa Nagai, Hidemine Obara, "Two-Battery HEECS Inverter with over 99.7\% Efficiency at $2.2 \mathrm{~kW}$ Output and Measurement Accuracy Based on Loss Breakdown”, IEEJ J. Industry Applications, Vol.9, No.6, pp.663-673, 2020.

(5) T. Nonaka, A. Toyota, and M. Ohto, "Technical Development of Concentrated Flux IPM Motor," Journal of the Japan Society of Applied Electromagnetics and Mechanics, Vol.24, No.4 pp.323-330, 2016. (in Japanese)

(6) T. Nonaka, S. Makino, and M. Ohto, "Research on Efficient Thermal Cooling Structure of a Motor," IEEJ Trans. IA, Vol.136, No.6, pp.385-391, 2016. (in Japanese)

(7) T. Nonaka, M. Hirayama, and M. Ohto, "Evaluation of rotor core made of high strength steel plates for IPM motor," Journal of the Japan Society of Applied Electromagnetics and Mechanics, Vol.25, No.2, pp.211-217, 2017. (in Japanese)

(8) A. Nishizawa, "Latest technology trends for electric aircraft motors," TECHFRONTEER 2018, B4-1-8, p15, 2018. (in Japanese)

(9) Y. Nishikawa, T. Kojima, T. Segawa, K. Tanimoto, T. Ogawa, K. Kinjo, "Highly Efficient Motor Using Soft Magnetic Material with Super-Low Iron Loss," Panasonic Technical Journal, Vo.62, No.2 , Nov. 2016. (in Japanese)

(10) T. Takeuchi," Electromechanical design", Ohmsha, (Since 1953) (in Japanese)

(11) S. Makino, and T. Nonaka, "Research of the Motor with Nanocrystalline Soft Magnetic Alloy Stator Cores,", IEEE Transactions on Industry Applications, 3-30, pp. III-259-262, 2019. (in Japanese)

(12) "Development of high saturation magnetic flux density, low loss soft magnetic material powder by NANOMET crushed," it is the theme of the project, "the program for strategic energy-saving technology innovation" subsidized by the NEDO, for the first public offering in 2019 . https://www.nedo.go.jp/content/100882662.pdf (in Japanese)

(13) T. Nonaka, S. Makino, "Research on Stator Core with Crushed pieces of Nanocrystalline Soft Magnetic Alloy,” ICEMS2020, LS1G-3, Nov. 2020

Tuyoshi Nonaka (Member) received B.E. degrees in electrical

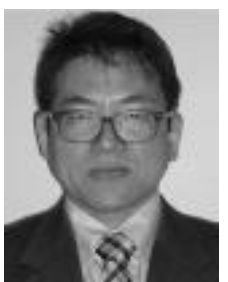

(Member) received B.E. degrees in electrical
engineering from Kyushu University, Fukuoka, Japan, in 1983, and received Ph.D. degrees in electrical engineering from Kagoshima University, Kagoshima, Japan, in 2018, respectively. In 2001, he joined Yaskawa Electric Corporation, Kitakyushu, Japan, where he is currently with the Motor Actuator Development Dept., Corporate R\&D Center. His current research interests include the design and development of electromagnetic rotating machine. He is a member of the Institute of Electrical Engineers of Japan.



(Member) received B.E. and M.E. degrees in mechanical engineering from Kyushu Institute of Technology, Kitakyushu, Japan, in 2002 and 2004, and received $\mathrm{Ph} . \mathrm{D}$. degrees in electrical engineering from Nagasaki University, Nagasaki, Japan, in 2017, respectively. In 2007, he joined Yaskawa Electric Corporation, Kitakyushu, Japan, where he is currently an Assistant Manager with the Motor Actuator Development Dept., Corporate R\&D Center. His current research interests include the design and development of rotary and linear motors. He is a member of the Institute of Electrical Engineers of Japan. 